\title{
PENERAPAN ALGORITMA GENETIK UNTUK OPTIMASI POLA PENYUSUNAN BARANG DALAM RUANG TIGA DIMENSI
}

\author{
Eddy Triswanto Setyoadi, ST., M.Kom.*
}

\begin{abstract}
ABSTRAK
Melakukan optimasi dalam pola penyusunan barang di dalam ruang tiga dimensi harus dapat dilakukan untuk menekan biaya seperti biaya pengiriman, biaya sewa gudang dan sebagainya. Algoritma Genetik sebagai metode pencarian solusi yang berpatokan pada seleksi alam untuk mendapatkan sebuah individu dengan susunan gengen terbaik, mampu memberikan solusi bagaimana pola susunan barang dioptimalkan melalui proses iterasi sampai beberapa generasi dengan operatornya yaitu crossover dan mutasi. Dengan menginputkan spesifikasi ruang dan barang-barang beserta nilai parameter Algoritma Genetik, proses opotimasi akan menemukan pola susunan barang dengan fitness terbaik, yaitu semakin sedikit ruang kosong yang tersisa.
\end{abstract}

Kata Kunci: Optimasi, Penyusunan Barang, Algorita Genetik.

\section{PENDAHULUAN}

Pada saat ini, efisiensi pada segala bidang di dalam dunia usaha sangat dibutuhkan. Hal ini biasanya dilakukan dengan cara menekan biaya pengeluaran dengan tujuan untuk meningkatkan laba yang akan didapat oleh suatu perusahaan. Salah satu faktor yang sering menimbulkan besarnya biaya pengeluaran dalam dunia usaha adalah proses pengiriman barang dari suatu tempat ketempat yang lain.

\subsection{Latar Belakang}

Kasus yang selalu sering terjadi pada suatu proses pengiriman barang adalah penyusunan letak barang dalam sebuah kontainer yang tidak optimal akan membutuhkan biaya yang berlipat karena dibutuhkan kontainer lain untuk mengangkut sisa barang yang seharusnya dapat dimasukkan hanya dalam satu kontainer saja apabila pola penyusunan barang didalamnya dioptimalkan.

Melihat kasus diatas dapat disimpulkan bahwa optimasi pola penyusunan barang pada suatu ruang mempunyai peran yang sangat penting dalam dunia usaha untuk menekan biaya pengeluaran seminimal mungkin. Dan untuk membantu penyelesaian masalah tersebut maka perlu dibangun suatu program aplikasi komputer (software komputer) yang ada penerapannya mampu memberikan jawaban atau solusi bagaimana seharusnya pola penyusunan barang pada ruang tiga dimensi, dimana pola penyusunan tersebut akan sulit ditemukan dengan cara manual.

\subsection{Perumusan Masalah}

Dari apa yang telah diuraikan pada latar belakang masalah maka perumusan masalah dari penelitian ini adalah bagaimana agar program aplikasi komputer yang dibuat pada penelitian ini mampu memberikan solusi terbaik tentang bagaimana pola penyusunan barang yang seoptimal mungkin dapat dilakukan pada ruang tiga dimensi.

\footnotetext{
* Staf Pengajar Program Studi S1-Sistem Informasi IKADO
} 


\subsection{Tujuan dan Manfaat Penelitian}

Tujuan dari penelitian ini adalah melakukan penerapan terhadap metode Algoritma Genetik dalam menangani kasus optimasi pola penyusunan barang dalam ruang tiga dimensi.

Manfaat yang diharapkan dengan adanya penelitian ini, agar dapat membantu masyarakat, terutama yang bergerak dalam bidang usaha, supaya dapat memberikan solusi terbaik bagaimana pola penyusunan barang yang optimal pada suatu ruang tiga dimensi.

\subsection{Hipotesis}

Sebagai metode pencarian solusi yang berpatokan pada seleksi alam, Algoritma Genetik diyakini mampu memberikan solusi terbaik mengenai optimasi pola penyusunan barang dalam ruang tiga dimensi.

\section{LANDASAN TEORI}

Pada penelitian ini teori-teori pendukung yang diperlukan dalam membantu penyelesaian penelitian ini adalah teori dasar mengenai Algoritma Genetik, relevansi Algoritma Genetik dalam optimasi pada pola penyusunan barang, dan penyimpanan data (database).

\subsection{Teori Dasar Algoritma Genetik}

Sebuah solusi yang dibangkitkan dalam Algoritma Genetik disebut sebagai kromosom, sedangkan kumpulan kromosom-kromosom tersebut disebut sebagai populasi. Sebuah kromosom dibentuk dari komponen-komponen penyusun yang disebut sebagai gen dan nilainya dapat berupa bilangan numerik, biner, simbol ataupun karakter, tergantung dari permasalahan yang ingin diselesaikan. Kromosom-kromosom tersebut akan berevolusi secara berkelanjutan yang disebut generasi. Dalam tiap generasi kromosom-kromosom tersebut dievaluasi tingkat keberhasilan nilai solusinya terhadap masalah yang ingin diselesaikan (fungsi obyektif) menggunakan ukuran yang disebut dengan fitness. Untuk memilih kromosom yang tetap dipertahankan untuk generasi selanjutnya dilakukan proses yang disebut dengan seleksi. Proses seleksi kromosom menggunakan konsep aturan evolusi Darwin yang telah disebutkan sebelumnya yaitu kromosom yang mempunyai nilai fitness tinggi akan memiliki peluang lebih besar untuk terpilih lagi pada generasi selanjutnya.

Kromosom-kromosom baru yang disebut dengan offspring, dibentuk dengan cara melakukan perkawinan antar kromosom-kromosom dalam satu generasi yang disebut sebagai crossover. Jumlah kromosom dalam populasi yang mengalami crossover ditentukan oleh parameter yang disebut dengan crossover threshold. Mekanisme perubahan susunan unsur penyusun makhluk hidup akibat adanya faktor alam yang disebut dengan mutasi direpresentasikan sebagai proses berubahnya satu atau lebih nilai gen dalam kromosom dengan suatu nilai acak. Jumlah gen dalam populasi yang mengalami mutasi ditentukan oleh parameter yang dinamakan mutasi threshold. Setelah beberapa generasi akan dihasilkan kromosom-kromosom yang nilai gen-gen nya konvergen ke suatu nilai tertentu yang merupakan solusi terbaik yang dihasilkan oleh Algoritma Genetik terhadap permasalahan yang ingin diselesaikan. 


\subsection{Relevansi Algoritma Genetik dalam Optimasi pada Pola Penyusunan Barang}

Parameter optimal atau tidak dapat dilihat dari sisi ruang kosong yang masih ada jika terdapat beberapa barang yang tidak muat untuk dimasukkan ke dalam ruang. Semakin sedikit ruang kosong yang ada dengan pola susunan barang tertentu (memperhatikan keseimbangan dan kebutuhan barang) akan menjadi solusi terbaik bagi masalah optimasi pola penyusunan barang. Berikut ini akan dijelaskan istilah Algoritma Genetik untuk:

- Gen

Gen merupakan unit dasar pembawa factor genetik yang menyusun sebuah kromosom atau individu. Gen mewakili satu barang didalam kromosom.

- Allele

Allele adalah nilai yang mungkin dalam sebuah gen. allele setiap gen adalah kode barang.

- Locus atau Loci

Locus atau Loci adalah posisi gen dalam suatu kromosom atau individu.

- Genotip

Genotip adalah representasi urutan allele yang membentuk sebuah individu atau kromosom. Genotip digambarkan sebagai rangkaian kode barang dalam kromosom.

- Kromosom

Kromosom adalah sederetan gen dalam jumlah tertentu yang merupakan pembawa utama informasi genetik. Kromosom diperlukan untuk memberikan gambaran suatu individu dalam populasi. Terdapat 4 macam representasi kromosom, yaitu: biner, integer, floating-point, dan path.

- Phenotip

Phenotip adalah representasi fisik hasil decoding genotip. Phenotip digambarkan sebagai rangkaian kode barang dalam kromosom untuk disusun kedalam ruang.

- Evaluasi

Proses penyusunan barang (gen) dalam ruang untuk mendapatkan fitness dari setiap individu.

- Populasi

Populasi merupakan kumpulan dari sejumlah individu atau kromosom. Ukuran populasi (jumlah individu) adalah sama untuk setiap generasi.

- Generasi

Generasi merupakan tingkatan keturunan sebuah populasi.

- Offspring

Offspring merupakan individu baru hasil adaptasi.

- Crossover

Crossover merupakan proses menggabungkan ciri dari dua kromosom parent untuk membentuk offspring dengan menukar segmen-segmen yang berhubungan pada parent-nya.

- Mutasi

Mutasi adalah proses mengubah satu atau lebih gen dari kromosom parent dimana gen dipilih secara random.

- Fitness

Fitness adalah nilai atau ukuran dari suatu individu atau kromosom. Fitness yang baik maka akan tetap dipertahankan sedangkan yang jelek maka akan disingkirkan. 
- Seleksi

Seleksi adalah proses pemilihan individu atau kromosom terbaik (dengan nilai fitness terbaik) yang nantinya digunakan sebagai parent.

\subsection{Database}

Database merupakan kumpulan dari data yang saling berhubungan satu dengan yang lainnya, tersimpan diperangkat keras komputer dan digunakan perangkat lunak untuk memanipulasinya. Database menjadi komponen utama dalam membangun sebuah sistem yang menyangkut pendokumentasian data.

\section{METODE PENELITIAN}

Pada penelitian ini, perihal yang perlu diperhatikan dalam mencapai keberhasilan terhadap penelitian yang dilakukan adalah dengan meneliti bagaimana cara penyusunan barang dalam sebuah ruang tiga dimensi dan bagaimana cara perhitungan nilai fitness sebagai nilai yang akan diolah oleh algoritma genetik.

\subsection{Penyusunan Barang dalam Ruang}

Penerapan Algoritma Genetik dalam proses penyusunan barang yaitu dengan meletakkan secara alami barang-barang yang diwakili oleh kode barang pada gengen dalam satu kromosom mulai gen pertama sampai gen terakhir. Peletakan secara alami diartikan bahwa proses peletakan barang hanya memperhatikan bisa tidaknya suatu barang pada gen masuk ke dalam ruang dengan space tertentu. Jika space tertentu tidak dapat memenuhi panjang, lebar dan tinggi barang maka akan dicari koordinat lain dalam ruang sampai barang tersebut bisa masuk sepenuhnya kedalam ruang kecuali koordinat telah mencapai panjang, lebar dan tinggi maksimal dari ruang. Apabila sudah tidak ada space kosong untuk menampung suatu barang maka barang tersebut akan disimpan dalam tabel sisa barang.

Proses penyusunan barang ini dilakukan berulang-ulang sebanyak kromosom yang ada pada setiap generasi. Mulai dari gen pertama sampai gen terakhir dalam variabel kromosom dilakukan langkah-langkah sebagai berikut :

1. Pencarian Tempat Kosong

Pada intinya proses ini bekerja untuk mencari koordinat kosong dalam ruang (koordinat $\mathrm{x}, \mathrm{y}, \mathrm{z}$ ) yang diwakili oleh variabel posisi. Saat ditemukan satu koordinat kosong dalam variabel posisi (misalnya posisi[1,1,1]=") maka akan dipanggil procedure tempat_kosong untuk mencari tempat kosong lainya sejauh panjang, lebar dan tinggi barang. Jika terpenuhi, maka variabel masuk (boolean) diisi true yang artinya proses dapat dilanjutkan ke tahap berikutnya. Prioritas penempatan barang dalam ruang yang didahulukan adalah pertama sejajar sumbu X (lebar ruang), kemudian sejajar sumbu Y (tinggi ruang), kemudian ketiga sejajar sumbu Z (panjang ruang).

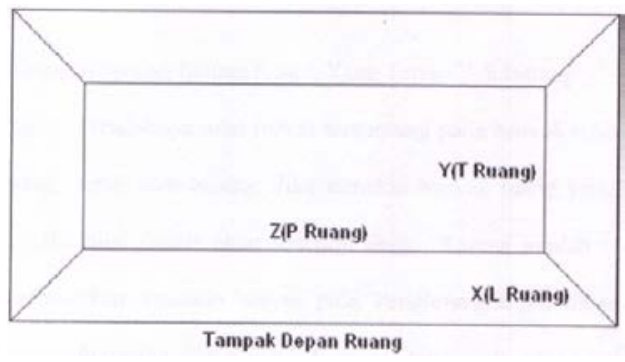

Gambar Ruang 3 Dimensi 
2. Pengisian Koordinat Ruang

Jika pencarian tempat kosong menghasilkan nilai variabel masuk=true, maka pengisian koordinat ruang akan dilakukan dengan cara menandai koordinat ruang sejauh panjang, lebar, tinggi suatu barang dengan kode barang tersebut. Dan apabila sudah terisi maka barang lain tidak boleh menempati koordinat tersebut.

3. Pengecekan Beban Maksimal Ruang

Pengecekan ini dilakukan untuk memastikan apakah berat seluruh barang yang telah disusun kedalam suatu ruang beratnya mampu untuk ditampung oleh beban maksimal ruang tersebut.

\subsection{Penghitungan Fitness}

Setelah proses penyusunan barang kedalam ruang selesai dilakukan maka proses selanjutnya adalah menghitung nilai fitness dari setiap pola susunan tersebut. Ada tiga teknik dalam menghitung nilai fitness dari setiap pola susunan barang yaitu:

1. Perhitungan Jumlah Satuan Ruang Yang Terisi Oleh Barang

Tingginya rendahnya nilai.fitness tergantung pada banyak tidaknya satuan ruang yang terisi oleh barang. Jika semakin banyak ruang yang terisi oleh barang maka nilai fitness akan semakin tinggi. Karena jumlah barang yang dapat dimasukkan semakin banyak pula. Penghitungan jumlah satuan ruang yang terisi oleh barang dibagi menjadi empat tahap yaitu : $1 / 4$ tinggi ruang, $1 / 2$ tinggi ruang, $3 / 4$ tinggi ruang, dan seluruh ruang. Penghitungan fitness dalam $1 / 4,1 / 2$, dan $3 / 4$ tinggi ruang dimaksudkan untuk mengantisipasi apabila terdapat fitness yang sama besar dari dua kromosom atau lebih. Untuk lebih memperjelas perhatikan contoh kasus dibawah ini :
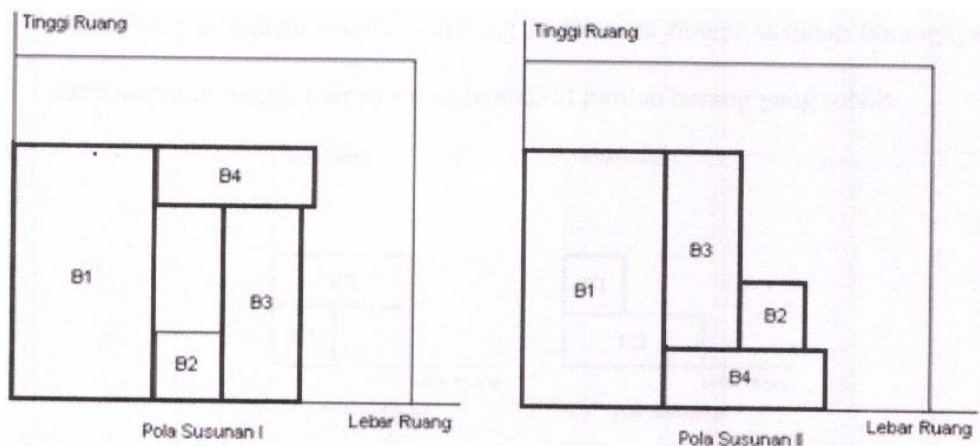

Gambar Contoh Hasil Fitness Yang Sama Besar

Pada gambar 3.5. dapat dilihat bahwa fitness yang didapat pada pola susunan I dan pola susunan II adalah sama besar jika dipakai teknik menghitung jumlah satuan ruang yang terisi oleh barang, karena seluruh barang dapat dimasukkan ke dalam ruang. Tetapi jika dilihat secara tampilan tiga dimensi, maka pola susunan II lebih baik dibanding pola susunan I karena pada pola susunan satu terdapat rongga kosong diantara tumpukan barang. Oleh karena diperlukan pnghitungan fitness dalam $1 / 4,1 / 2$, dan $3 / 4$ tinggi ruang yang memberi satuan terkecil tidak terisi oleh barang untuk dijadikan pola susunan dengan fitness terbaik.

2. Perhitungan Jumlah Barang Yang Seimbang Di Dalam Ruang

Penghitungan fitness dilakukan dengan cara menghitung jumlah barang yang menempati posisinya secara seimbang (titik berat barang berada diatas barang lain, kecuali barang dilantai ruang), jika semakin banyak barang yang menempati posisinya secara seimbang maka nilai fitness susunan barangnya akan semakin tinggi, karena semakin sedikit jumlah barang yang roboh. 

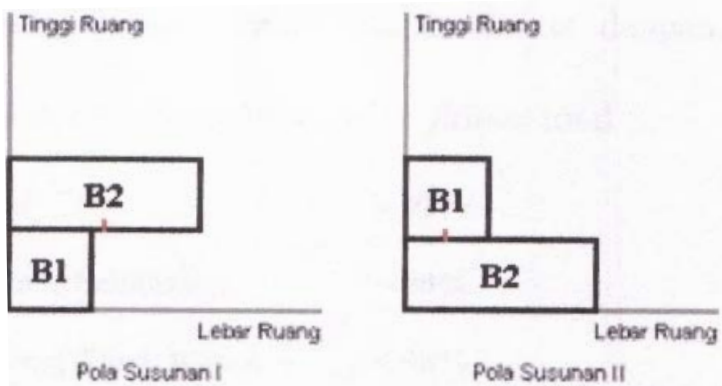

Gambar Pola Susunan I (tidak seimbang), Pola Susunan II (seimbang)

\section{Perhitungan Jumlah Barang Yang Tidak Rusak Didalam Ruang}

Cara memperoleh nilai fitness yaitu menghitung banyaknya barang yang tidak hancur dalam tumpukan. Tidak hancurnya suatu barang diketahui dengan cara menghitung jumlah berat barang lain yang berada diatas barang tersebut apabila berat barang-barang diatasnya mampu ditampung oleh beban tumpukan barang tersebut maka barang tesebut tidak hancur. Dan semakin banyak barang yang tidak hancur maka nilai fitness akan semakin tinggi.

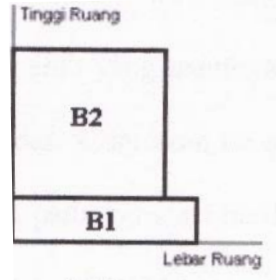

Pola Susunan I

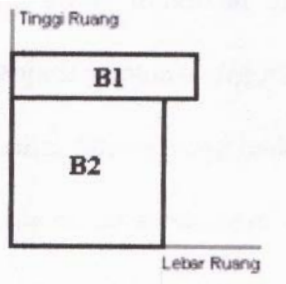

Pola Susunan II

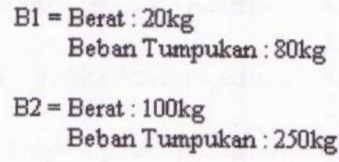

$\mathrm{B} 1=$ Berat $: 20 \mathrm{~kg}$ Beban Tumpukan : $80 \mathrm{~kg}$

$\mathrm{B} 2=$ Berat : $100 \mathrm{~kg}$

Beban Tumpukan : $250 \mathrm{~kg}$

Gambar Pola Susunan I (B1 rusak) Pola Susunan II (B1 tidak rusak)

Setelah semua teknik pencarian fitness dilakukan maka nilai-nilai fitness tersebut digabungkan menjadi satu untuk mendapatkan nilai fitness akhir dari susunan barang dimana fitness terbaik adalah fitness dengan nilai tertinggi. Berikut ini adalah contoh cara menghitung nilai fitness total :

$\begin{array}{ll}\text { Fitness Total Ruang terisi } & =92 \% \\ \text { Fitness Jumlah Barang Yang Seimbang } & =80 \% \\ \text { Fitness Jumlah Barang Yang Tidak Rusak } & =98 \% \\ \text { Fitness Total } & =(92+80+98) / 3=90\end{array}$

Fitness total $=($ Fitness ruang_terisi + fitness barang seimbang + fitness barang_utuh) / 3

\section{Rumus Menghitung Fitness Total}

\section{UJI COBA}

Hasil dari penelitian yang dilakukan telah diuji cobakan melalui software yang dibuat dengan tujuan untuk memudahkan dalam melakukan eksperimen, sebagai salah satu contoh diberikan kasus dengan data-data sebagai berikut: 
- Data Ruang

Tabel Inputan Data Ruang

\begin{tabular}{|c|c|c|c|c|}
\hline Panjang & Lebar & Tinggi & Volume & Beban Max \\
\hline $5 \mathrm{~m}$ & $3 \mathrm{~m}$ & $3 \mathrm{~m}$ & $45 \mathrm{~m}^{3}$ & $10.000 \mathrm{~kg}$ \\
\hline
\end{tabular}

- Data Barang

Tabel Inputan Data Barang

\begin{tabular}{|c|c|c|c|c|c|c|}
\hline Kode & $\mathrm{P}(\mathrm{cm})$ & $\mathrm{L}(\mathrm{cm})$ & $\mathrm{T}(\mathrm{cm})$ & Berat(kg) & Beban(kg) & Jumlah \\
\hline B1 & 200 & 100 & 70 & 30 & 100 & 10 \\
\hline B2 & 100 & 60 & 50 & 20 & 100 & 20 \\
\hline B3 & 80 & 50 & 40 & 10 & 50 & 20 \\
\hline B4 & 120 & 90 & 60 & 30 & 90 & 20 \\
\hline B5 & 50 & 40 & 30 & 5 & 20 & 30 \\
\hline
\end{tabular}

- Data Parameter Algoritma Genetik

Tabel Inputan Data Parameter Algoritma Genetik

\begin{tabular}{|c|c|c|c|}
\hline Generasi Max & Jumlah Kromosom & Mutasi Threshold & Crossover Threshold \\
\hline 100 & 20 & 0.3 & 0,4 \\
\hline
\end{tabular}

Contoh kasus dengan data yang telah dijabarkan sebelumnya, dengan memanfaatkan metode Algoritma Genetik akan menghasilkan beberapa informasi yang diperlukan, berikut informasi-informasi yang dihasilkan dari contoh kasus tersebut:

Tabel Fitness Pola Susunan Barang

\begin{tabular}{|l|c|}
\hline \multicolumn{1}{|c|}{ Informasi } & Nilai \\
\hline Fitness Ruang Terisi & $91 \%$ \\
\hline Fitness Barang Seimbang & $97 \%$ \\
\hline Fitness Barang Utuh & $90 \%$ \\
\hline Fitness Total & $92,667 \%$ \\
\hline Sisa Barang & B2(3) \\
\hline
\end{tabular}

Tabel Output Data Pola Susunan Barang

\begin{tabular}{|c|c|c|c|c|c|c|c|c|c|c|c|}
\hline $\begin{array}{c}\text { Kode } \\
\text { Barang }\end{array}$ & $X$ & $Y$ & Z & $\begin{array}{c}\text { Kode } \\
\text { Barang }\end{array}$ & $X$ & $Y$ & Z & $\begin{array}{c}\text { Kode } \\
\text { Barang }\end{array}$ & $x$ & $Y$ & Z \\
\hline B4 & 0 & 0 & 0 & B5 & 0 & 240 & 60 & B3 & 200 & 0 & 260 \\
\hline B4 & 60 & $\theta$ & $\theta$ & $\mathrm{B} 1$ & $\theta$ & 140 & 180 & B3 & 240 & $\theta$ & 260 \\
\hline B4 & 120 & $\theta$ & $\odot$ & B5 & 50 & 240 & 60 & B1 & $\theta$ & 140 & 280 \\
\hline B4 & 180 & $\theta$ & 0 & B5 & 100 & 240 & 60 & B3 & 200 & 50 & 260 \\
\hline B4 & 240 & $\theta$ & $\theta$ & B5 & 150 & 240 & 60 & B3 & 240 & 50 & 260 \\
\hline B4 & $\theta$ & 120 & $\theta$ & B5 & 200 & 240 & 60 & B3 & 200 & 100 & 260 \\
\hline B4 & 60 & 120 & $\theta$ & B5 & 250 & 240 & 60 & B3 & 240 & 100 & 260 \\
\hline B4 & 120 & 120 & $\theta$ & B5 & $\theta$ & 240 & 90 & B3 & 200 & 150 & 260 \\
\hline
\end{tabular}


Tabel Output Data Pola Susunan Barang (Lanjutan)

\begin{tabular}{|c|r|r|r|}
\hline $\begin{array}{c}\text { Kode } \\
\text { Barang }\end{array}$ & \multicolumn{1}{|c|}{ X } & Y & \multicolumn{2}{|c|}{} \\
\hline B4 & $18 \odot$ & $12 \odot$ & $\odot$ \\
\hline B4 & $24 \odot$ & $12 \odot$ & $\odot$ \\
\hline B4 & $\odot$ & $\odot$ & $9 \odot$ \\
\hline B4 & $6 \odot$ & $\odot$ & $9 \odot$ \\
\hline B4 & $12 \odot$ & $\odot$ & $9 \odot$ \\
\hline B4 & $18 \odot$ & $\odot$ & $9 \odot$ \\
\hline B4 & $24 \odot$ & $\odot$ & $9 \odot$ \\
\hline B4 & $\odot$ & $12 \odot$ & $9 \odot$ \\
\hline B4 & $6 \odot$ & $12 \odot$ & $9 \odot$ \\
\hline B4 & $12 \odot$ & $12 \odot$ & $9 \odot$ \\
\hline B1 & $\odot$ & $\odot$ & $18 \odot$ \\
\hline B4 & $18 \odot$ & $12 \odot$ & $9 \odot$ \\
\hline B4 & $24 \odot$ & $12 \odot$ & $9 \odot$ \\
\hline B5 & $\odot$ & $24 \odot$ & $\odot$ \\
\hline B5 & $5 \odot$ & $24 \odot$ & $\odot$ \\
\hline B5 & $10 \odot$ & $24 \odot$ & $\odot$ \\
\hline B5 & $15 \odot$ & $24 \odot$ & $\odot$ \\
\hline B5 & $20 \odot$ & $24 \odot$ & $\odot$ \\
\hline B1 & $\odot$ & $7 \odot$ & $18 \odot$ \\
\hline B5 & $25 \odot$ & $24 \odot$ & $\odot$ \\
\hline B5 & $\odot$ & $24 \odot$ & $3 \odot$ \\
\hline B5 & $5 \odot$ & $24 \odot$ & $3 \odot$ \\
\hline B5 & $10 \odot$ & $24 \odot$ & $3 \odot$ \\
\hline B5 & $15 \odot$ & $24 \odot$ & $3 \odot$ \\
\hline B5 & $20 \odot$ & $24 \odot$ & $3 \odot$ \\
\hline B5 & $25 \odot$ & $24 \odot$ & $3 \odot$ \\
\hline & & & \\
\hline
\end{tabular}

\begin{tabular}{|c|r|r|r|}
\hline $\begin{array}{c}\text { Kode } \\
\text { Barang }\end{array}$ & \multicolumn{1}{|c|}{ X } & \multicolumn{1}{c|}{ Z } \\
\hline B5 & $5 \odot$ & $24 \odot$ & $9 \odot$ \\
\hline B5 & $10 \odot$ & $24 \odot$ & $9 \odot$ \\
\hline B1 & $\odot$ & $21 \odot$ & $18 \odot$ \\
\hline B5 & $15 \odot$ & $24 \odot$ & $9 \odot$ \\
\hline B5 & $20 \odot$ & $24 \odot$ & $9 \odot$ \\
\hline B5 & $25 \odot$ & $24 \odot$ & $9 \odot$ \\
\hline B5 & $\odot$ & $24 \odot$ & $12 \odot$ \\
\hline B5 & $5 \odot$ & $24 \odot$ & $12 \odot$ \\
\hline B5 & $10 \odot$ & $24 \odot$ & $12 \odot$ \\
\hline B5 & $15 \odot$ & $24 \odot$ & $12 \odot$ \\
\hline B5 & $20 \odot$ & $24 \odot$ & $12 \odot$ \\
\hline B1 & $\odot$ & $\odot$ & $28 \odot$ \\
\hline B5 & $25 \odot$ & $24 \odot$ & $12 \odot$ \\
\hline B3 & $20 \odot$ & $\odot$ & $18 \odot$ \\
\hline B3 & $24 \odot$ & $\odot$ & $18 \odot$ \\
\hline B3 & $20 \odot$ & $5 \odot$ & $18 \odot$ \\
\hline B3 & $24 \odot$ & $5 \odot$ & $18 \odot$ \\
\hline B3 & $20 \odot$ & $10 \odot$ & $18 \odot$ \\
\hline B3 & $24 \odot$ & $10 \odot$ & $18 \odot$ \\
\hline B1 & $\odot$ & $7 \odot$ & $28 \odot$ \\
\hline B3 & $20 \odot$ & $15 \odot$ & $18 \odot$ \\
\hline B3 & $24 \odot$ & $15 \odot$ & $18 \odot$ \\
\hline B3 & $20 \odot$ & $20 \odot$ & $18 \odot$ \\
\hline B3 & $24 \odot$ & $20 \odot$ & $18 \odot$ \\
\hline B3 & $20 \odot$ & $25 \odot$ & $18 \odot$ \\
\hline B3 & $24 \odot$ & $25 \odot$ & $18 \odot$ \\
\hline
\end{tabular}

\begin{tabular}{|c|r|r|c|}
\hline $\begin{array}{c}\text { Kode } \\
\text { Barang }\end{array}$ & $X$ & $Y$ & $Z$ \\
\hline B3 & $24 \odot$ & $15 \odot$ & $26 \odot$ \\
\hline B2 & $20 \odot$ & $20 \odot$ & $26 \odot$ \\
\hline B2 & $20 \odot$ & $25 \odot$ & $26 \odot$ \\
\hline B1 & $\odot$ & 210 & $28 \odot$ \\
\hline B2 & $20 \odot$ & $\odot$ & $34 \odot$ \\
\hline B2 & $20 \odot$ & $5 \odot$ & $34 \odot$ \\
\hline B2 & $20 \odot$ & $10 \odot$ & $34 \odot$ \\
\hline B2 & $20 \odot$ & $15 \odot$ & $34 \odot$ \\
\hline B2 & $20 \odot$ & $20 \odot$ & $36 \odot$ \\
\hline B2 & $20 \odot$ & $25 \odot$ & $36 \odot$ \\
\hline B2 & $\odot$ & $\odot$ & $38 \odot$ \\
\hline B1 & $\odot$ & $5 \odot$ & $38 \odot$ \\
\hline B2 & $6 \odot$ & $\odot$ & $38 \odot$ \\
\hline B2 & $12 \odot$ & $\odot$ & $28 \odot$ \\
\hline B2 & $\odot$ & $12 \odot$ & $38 \odot$ \\
\hline B2 & $6 \odot$ & $12 \odot$ & $38 \odot$ \\
\hline B2 & $12 \odot$ & $12 \odot$ & $38 \odot$ \\
\hline B2 & $\odot$ & $17 \odot$ & $28 \odot$ \\
\hline B2 & $6 \odot$ & $17 \odot$ & $38 \odot$ \\
\hline B2 & $12 \odot$ & $17 \odot$ & $38 \odot$ \\
\hline B1 & $\odot$ & $22 \odot$ & $38 \odot$ \\
\hline
\end{tabular}

Pada pengujian diatas inputan data parameter Algoritma Genetik (populasi dan jumlah individu atau kromosom) menggunakan jumlah yang besar bertujuan untuk membuka peluang untuk menciptakan suatu kromosom yang memiliki susunan gen dengan nilai fitness yang terbaik. Berikut ini beberapa hasil uji coba dengan data-data yang sama dengan data-data pada pengujian sebelumnya, akan tetapi berbeda dalam jumlah kromosom dan jumlah generasi:

1. Dengan jumlah generasi $=50$, jumlah kromosom $=10$. Maka hasil terbaik fitness yang didapatkan sebagai berikut:

Tabel Fitness Pola Susunan Barang (2)

\begin{tabular}{|l|c|}
\hline \multicolumn{1}{|c|}{ Informasi } & Nilai \\
\hline Fitness Ruang Terisi & $69 \%$ \\
\hline Fitness Barang Seimbang & $72 \%$ \\
\hline Fitness Barang Utuh & $66 \%$ \\
\hline Fitness Total & $69 \%$ \\
\hline Sisa Barang & B1(10), B2(2), B3(5), B4(6) \\
\hline
\end{tabular}


2. Dengan jumlah generasi $=50$, jumlah kromosom $=20$. Maka hasil terbaik fitness yang didapatkan sebagai berikut:

Tabel Fitness Pola Susunan Barang (3)

\begin{tabular}{|l|c|}
\hline \multicolumn{1}{|c|}{ Informasi } & Nilai \\
\hline Fitness Ruang Terisi & $91 \%$ \\
\hline Fitness Barang Seimbang & $97 \%$ \\
\hline Fitness Barang Utuh & $90 \%$ \\
\hline Fitness Total & $92,667 \%$ \\
\hline Sisa Barang & B2(3), B3(3), B4(4) \\
\hline
\end{tabular}

\section{KESIMPULAN DAN SARAN}

Pada akhir dari penelitian ini, dapat ditarik beberapa kesimpulan dan saran yang dapat dilakukan dalam rangka mengembangkan hasil penelitian ini di kelak kemudian hari.

\subsection{Kesimpulan}

Dari penelitian yang telah dilakukan dalam melakukan penerapan Algoritma Genetik untuk optimasi pola penyusunan barang dalam ruang tiga dimensi, dapat ditarik beberapa kesimpulan sebagai berikut:

1. Penerapan Algoritma Genetik dalam mencari pola penyusunan barang dalam ruang tiga dimensi dianggap mampu memberikan solusi penyusunan barang yang optimal.

2. Crossover dan mutasi adalah operator Algoritma Genetik yang sangat berguna dalam menghasilkan individu-individu baru dengan nilai fitness yang semakin baik dalam setiap generasi.

3. Semakin banyak jumlah individu pada suatu populasi dan didukung oleh banyaknya generasi maka semakin memperbesar probabilitas kemungkinan lahirnya individu dengan nilai fitness terbaik.

4. Dalam penelitian ini, proses penyusunan barang dalam ruang tiga dimensi memperhatikan beban maksimal yang dapat ditampung oleh ruang, beban tumpukan maksimal yang dapat ditampung oleh barang serta keseimbangan susunan barang agar tidak roboh.

5. Pencarian fitness diperoleh dari gabungan nilai fitness berikut ini:

- Prosentase jumlah satuan ruang yang terisi.

- Prosentase jumlah barang yang seimbang.

- Prosentase jumlah barang yang tidak rusak akibat tidak mampu menahan beban tumpukan.

\subsection{Saran}

Penelitian yang telah dilakukan ini memungkinkan untuk dikembangkan lebih lanjut seperti menambahkan suatu fungsi untuk merotasi barang serta menambahkan bentuk barang tiga dimensi lainnya yang memungkinkan untuk dapat dicari pola susunannya didalam suatu ruang tiga dimensi. 


\section{DAFTAR PUSTAKA}

Gunawan. Handout Matakuliah Fuzzy Genetic Algorithms, Institut Informatika Indonesia. 2007 Nugroho, Bunafit. Database Relational Dengan MySql, Andi, Yogyakarta. 2005. 